\title{
Molecular characterization of a new plasmid-encoded SHV-type $\beta$-lactamase (SHV-2 variant) conferring high-level cefotaxime resistance upon Klebsiella pneumoniae
}

\author{
Andreas Podbielski, ${ }^{1 *}$ Jutta Schönling, ${ }^{1}$ Beate Melzer, ${ }^{1}$ Klaus Warnatz $^{2}$ and \\ HANS-GEORG LEUSCH ${ }^{2}$ \\ ${ }^{1}$ Institute of Medical Microbiology and ${ }^{2}$ Institute of Medical Immunology, University of Aachen, Pauwelsstrasse 30 , \\ 5100 Aachen, FRG
}

(Received 6 August 1990; revised 15 November 1990; accepted 27 November 1990)

\begin{abstract}
Between 1986 and 1988, multiresistant Klebsiella pneumoniae strains exhibiting high-level cefotaxime resistance were isolated from patient specimens particularly of the intensive care units of the Aachen Technical University Hospital. The resistance gene responsible was shown to be encoded on a conjugative $66 \mathrm{~kb}$ plasmid designated pZMP1. The MIC values for cefotaxime of the original isolates and the transconjugants were $>128 \mathrm{mg} \mathrm{I}^{-1}$ and 64 $\mathrm{mg} \mathrm{l}^{-1}$, respectively. Isoelectric focusing of protein preparations from the transconjugants showed a $\beta$-lactamase with a pI of 7.6. A $3.6 \mathrm{~kb} \mathrm{BamHI}$ fragment containing the $\beta$-lactamase gene was cloned into pLG339 resulting in the recombinant plasmid pZMP1-1. A restriction map of the cloned insert was established and PstI subfragments of the insert were further subcloned into pBGS18. The nucleotide sequence of the complete $3.6 \mathrm{~kb}$ fragment was determined. Within $3663 \mathrm{bp}$ an open reading frame of $858 \mathrm{~kb}$ was found to show $99 \%$ homology to the SHV-2 and -3 nucleotide sequences. The deduced amino acid sequence differed in one and two positions, respectively, from these established SHV enzymes. The $3^{\prime}$ noncoding sequence exhibited nearly perfect homology to that of SHV-2, but the $5^{\prime}$ upstream sequence showed homology of less than $50 \%$ to the corresponding SHV-2 sequence, indicating an altered promoter region of the variant SHV-enzyme. Kinetic analysis of the $\beta$-lactamase revealed a 50-100\% elevated hydrolytic effectivity on cefotaxime in comparison to other SHV enzymes. Cefoxitin, ceftazidime, aztreonam and imipenem were not hydrolysed by the enzyme. The variant enzyme was inhibited by commonly available $\beta$-lactamase inhibitors. Clavulanic acid had the highest affinity for the enzyme and the greatest effectivity in blocking its action. Based on the genetic and kinetic data we propose to classify the enzyme as a new variant $\beta$-lactamase of the SHV-type and name it SHV-2a.
\end{abstract}

\section{Introduction}

In general Klebsiella pneumoniae is only moderately susceptible to penicillins as a result of a chromosomally encoded $\beta$-lactamase (Labia et al., 1979). In addition, strains sometimes contain plasmid-encoded $\beta$-lactamases of the SHV type, and less often of the TEM type (Roy et al., 1985).

$\beta$-Lactamase SHV-1, first detected by Pitton (1972) and designated as such by Matthew et al. (1979),

Abbreviations: CTX, cefotaxime; CTZ, ceftazidime; IEF, isoelectric focusing; ORF, open reading frame; pHMB, $p$-hydroxymercuribenzoate.

The nucleotide sequence data reported in this paper have been submitted to GenBank and have been assigned the accession number X53817. broadens the resistance of its producer to first-generation cephalosporins. Since the first report (Knothe et al., 1983), the emergence of resistance of Klebsiella oxytoca and $K$. pneumoniae isolates to third-generation cephalosporins, namely cefotaxime (CTX) and ceftazidime (CTZ), have been described with increasing frequency [Kliebe et al., 1985 (SHV-2); Jarlier et al., 1988 (SHV-3); Buré et al., 1988 (SHV-4); Gutmann et al., 1989 (SHV5)]; in Germany these isolates remained rather scarce (Podschun et al. 1986). The minimum inhibitory concentrations (MICs) in $\mathrm{mg}^{-1}$ of CTX for the original isolates are as follows: SHV-1, 0.03; SHV-2 and SHV-3, 4; SHV4 and SHV-5, 8; those of CTZ are: SHV-1, $0 \cdot 13$; SHV-2 and SHV-3, 4; SHV-4 and SHV-5, 64. Mutations of the original SHV-1 enzyme were shown to be the reason for the development of increasing resistance (Barthélémy et al. 1988b). Recently the nucleotide sequences of the 
genes of SHV-3 (Nicolas et al., 1989), SHV-2 (Podbielski \& Melzer, 1990), an SHV-2 variant (Garbarg-Chenon et al., 1990), SHV-1 (Mercier \& Levesque, 1990) and OHIO-1 (Shlaes et al., 1990) were established. Here we characterize another plasmid-encoded $\beta$-lactamase and the corresponding gene conferring unusually high-level CTX resistance to its $K$. pneumoniae host (MIC >128 mg $\left.1^{-1}\right)$. It first appeared in Aachen University Hospital in 1986, reached its highest prevalence in 1987 and slowly disappeared in 1988, perhaps due to a change of antibiotic regimens in the intensive-care units (Podbielski et al., 1988, 1990).

\section{Methods}

Bacterial strains and growth conditions. Nineteen cefotaxime-resistant $\left(\mathrm{CTX}^{\mathrm{R}}\right) \mathrm{K}$. pneumoniae strains were isolated from blood cultures, tracheal aspirates, wound and urine specimens collected predominantly in the intensive care units of our hospital from spring 1987 to summer 1988. Identification to species level was performed by using conventional techniques and API $20 \mathrm{E}$ (api bioMérieux), determination of clusters differing in biochemical markers by using API $50 \mathrm{CHE}$.

For conjugation experiments a nalidixic-acid-resistant Escherichia coli mutant, W3110 (Kliebe et al., 1985), was used, and for transformation experiments an $E$. coli $\mathrm{HB} 101$ derivative, DH5 $\alpha$ (Gibco BRL). Strains were passaged on DST agar (Oxoid) containing $10 \mathrm{mg}$

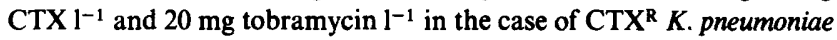
wild-types and 4-20 mg CTX ${ }^{-1}$ in the case of transformants or transconjugants. Cultures used for protein peparations for $\beta$-lactamase assays were grown in Iso-sensitest broth (Oxoid).

Selection for recombinant clones was performed on $\mathrm{H}$-agar (Boehringer Mannheim) containing X-Gal and ITPG and $4 \mathrm{mg}$ CTX $\mathrm{1}^{-1}$ or $30 \mathrm{mg}$ kanamycin $\mathrm{1}^{-1}$, respectively.

Disk sensitivity testing, MIC determination and antibiotics. Conventional disk sensitivity testing was done on Mueller-Hinton agar (Oxoid) according to DIN standards using antibiotic disks supplied by Becton-Dickinson. MICs were determined at least in triplicate by a microdilution method according to the NCCLS standard methods (Podbielski et al., 1989) and additionally by the use of the Sensitititre system (Radiometer). Restoration of susceptibility by use of $\beta$ lactamase inhibitors was screened according to Gutmann et al. (1989). Antimicrobial agents were kindly provided as follows. Benzylpenicillin, ampicillin, cefotiam, cefmenoxime and doxycycline were from Grünenthal; cefotaxime (CTX), desacetylcefotaxime and cefpirome were from Hoechst; ceftazidime (CTZ) was from Glaxo; mezlocillin and ciprofloxacine were from Bayer; ceftriaxone and sulfamethoxazole-trimethoprim were from Hoffmann La Roche; moxalactam and tobramycin were from Lilly; cefoxitin and imipenem were from MSD; cefotetan was from ICI; aztreonam was from Squibb; gentamicin was from E. Merck; cephaloridine was from Sigma; cefazolin was from Boehringer Mannheim; clavulanic acid was from Beecham; sulbactam was from Pfizer; tazobactam was from Taiho-Lederle.

$\beta$-Lactamase assays. $\beta$-Lactamases were prepared from clinical isolates, transconjugants and transformants after complete disruption of cells by sonication (Vibra Cell VC 300, Sonics \& Materials), filtration of cell lysates through $0.22 \mu \mathrm{m}$ pore size filters and overnight dialysis against $10 \mathrm{~mm}-\mathrm{NaCl}$ at $4{ }^{\circ} \mathrm{C}$. Protein content of the crude extracts was determined with $\mathrm{BCA}$ reagent (Pierce) according to the instructions of the manufacturer.

Analytical isoelectric focusing (IEF) was performed by the method of Matthew et al. (1975) using TEM-1, TEM-2, PSE-1, PSE-2, OXA-1, SHV-1 and Enterobacter cloacae P99 chromosomal $\beta$-lactamase as pI standards (Kliebe et al., 1985) and nitrocefin for visualization.

Determination of specific CTX hydrolysis by single bands from IEF was carried out by cutting slabs containing these bands from the gel, placing them as a whole into the cuvette containing phosphate-buffered saline pH 7.2 and $75 \mu \mathrm{M}$-CTX and performing the assays as described below.

Kinetic analysis of $\beta$-lactamases were performed at least in duplicate according to the recommendations of Bush \& Sykes (1986) using 10, 20, 50,100 and $200 \mu \mathrm{M}$-substrate dissolved in phosphate-buffered saline of pH 7.2 monitored up to $30 \mathrm{~min}$ by a temperature-controlled $\left(37^{\circ} \mathrm{C}\right)$ Beckman DU-7 spectrophotometer. In the case of the cephalosporins appropriate wavelengths for monitoring enzyme activity were according to Seeberg et al. (1983); for desacetyl-CTX (264 nm), cefpirome (262 $\mathrm{nm})$ and imipenem (292 $\mathrm{nm})$ according to the manufacturer's information. In the case of penicillins the microacidimetric method of Ross \& O'Callaghan (1975) was used. In all cases an aliquot of the crude enzyme extract exhibiting a specific activity of $0.5 \mathrm{nmol}$ cephaloridine $\min ^{-1}(\mu \mathrm{g} \text { protein })^{-1}$ was placed into the assay; the total assay volume was always $800 \mu l$

Apparent saturation velocity $(V)$ and $K_{\mathrm{m}}$ values were calculated by using the Lineweaver-Burk transformation and linear regression of the data, rejecting sets of measurements with $r$ values $<0.98$. Apparent $K_{\mathrm{i}}$ values were calculated by the method of Waley (1982) using cephaloridine as a substrate at concentrations mentioned above. $I_{50}$ values were determined by nonlinear regression with $200 \mu \mathrm{M}-$ cephaloridine as a substrate. All inhibition experiments were performed with 5 min preincubation time for the inhibitor.

Inhibition by $p$-hydroxymercuribenzoate (pHMB, Sigma) was tested with $0.5 \mathrm{mM}$-pHMB in the assay, with $10 \mathrm{~min}$ preincubation and spectrophotometric measurement of hydrolysis of benzylpenicillin and cephaloridine each at a concentration of $250 \mu \mathrm{M}$.

Inhibition by 0.1 and $1 \mathrm{mM}$-EDTA was monitored as for inhibition by $\mathrm{pHMB}$.

Nucleic acid techniques. Plasmid DNA was extracted according to Birnboim (1983). For determining plasmid patterns, DNA restriction enzyme analysis by $0.7-1 \cdot 2 \%$ agarose gel electrophoresis was used; for Southern blotting onto nylon membranes conventional techniques (Sambrook et al., 1989) were applied. Restriction enzymes were supplied by Boehringer Mannheim, 'DNA' agarose Seakem by Biozyme and Biodyne B nylon membranes by Pall. DNA hybridization $\left(68^{\circ} \mathrm{C}, 6 \times \mathrm{SSC}\right)$ and non-radioactive detection were performed according to the instructions of the manufacturer of Chemiprobe (Biozyme). Cloning experiments with pLG339 (Stoker et al., 1982) and pBGS18 (Spratt et al., 1986) as vectors were carried out as described by Walker (1984), using the modified Kushner method (Hanahan, 1983) for transformation. Restriction endonuclease sites were determined by single and double digests and in case of $P$ st $I$ by time-dependent partial digestion using the $3.6 \mathrm{~kb} \mathrm{BamHI}$ fragment labelled with $[\gamma-32$ P]ATP (Amersham) at one 5' end (Brooks, 1987). Double-stranded plasmid DNA for sequencing was purified as above, followed by ethidium bromide/caesium chloride density-gradient centrifugation in a Beckman TLV $100 \mathrm{~K}$ rotor for $3 \mathrm{~h}$ at 100000 r.p.m. DNA sequencing was performed by the dideoxy-chain-termination method (Sanger et al., 1977) using the Pharmacia $T_{7}$ sequencing kit and $\left[\alpha^{-35} S\right] d A T P$ (Amersham) for labelling. Sequencing primers were synthesized on a Beckman 200 A DNA synthesizer. DNA sequences were analysed by the use of the PC-GENE program (Genofit/IntelliGenetics).

pBP60-1-2, a recombinant plasmid of pBGS8 and two adjacent 2.35 kb Pst I fragments from pBP60 encoding the SHV-2 gene, and pBP60, the natural plasmid from Klebsiella ozaenae 2180 containing the SHV-2 gene were kindly provided by C. Kliebe-Frisch, Institute of Medical Microbiology, University of Bonn, FRG. 


\section{Results}

Disk susceptibility testing, biochemical properties and plasmid pattern

Our attention was drawn to the $\mathrm{CTX}^{\mathrm{R}} K$. pneumoniae isolates by the uniform resistance pattern they showed in agar diffusion tests. The values of the disk susceptibility testing were in agreement with the MIC values shown in Table 1 . The common antibiotic resistance pattern of these strains was paralleled by the results of biotyping. They all exhibited a homogeneous API $20 \mathrm{E}$ code (5215773) and, with the exception of one isolate for tagatose, a uniform carbohydrate fermentation pattern when tested by the API 50 CHE biochemical test system.

All the $\mathrm{CTX}^{\mathrm{R}} K$. pneumoniae isolates possessed a $2.6 \mathrm{~kb}$ and a $66 \mathrm{~kb}$ plasmid, some additionally contained a plasmid of 4.4 or $4.8 \mathrm{~kb}$, and occasionally another one larger than $50 \mathrm{~kb}$. The small plasmids of 2.6 and $4.4 \mathrm{~kb}$ were at least partially homologous, since they hybridized to each other (data not shown). Both had one restriction site for BamHI and none for EcoRI, HindIII or PstI.
These small plasmids could be mobilized in transconjugation experiments and appeared to be cryptic in their natural host, whereas transformation into $E$. coli $\mathrm{DH} 5 \alpha$ led to expression of a $\beta$-lactamase of pI 4.8 . The $66 \mathrm{~kb}$ plasmid, which we call pZMP1, is conjugative, and after conjugation or transformation it conferred resistance to cefotaxime, but not to doxycycline and tobramycin, as monitored by MIC determination (see below). Its restriction endonuclease pattern for BamHI, EcoRI, HindIII and PstI differs completely from that of pBP60, which encodes the SHV-2 $\beta$-lactamase (data not shown), but is identical for all of the $\mathrm{CTX}^{\mathrm{R}}$ Klebsiella isolates tested.

\section{$\beta$-Lactamase patterns}

All the $\mathrm{CTX}^{\mathrm{R}} K$. pneumoniae isolates showed a $\beta$ lactamase of pI 7.6 in IEF; 13 isolates showed an additional one of pI 5.9.

Only the enzyme of pI 7.6, and not that of pI 5.9, hydrolysed CTX when using the corresponding gel slab

Table 1. MICs for selected $C T X^{\mathrm{R}} K$. pneumoniae isolates, and for $E$. coli transformants, transconjugants and recipients of conjugation

\begin{tabular}{|c|c|c|c|c|c|}
\hline \multirow[b]{2}{*}{ Antibiotic } & \multicolumn{5}{|c|}{ MIC (mg $\left.\mathrm{l}^{-1}\right)$ of antibiotics for : } \\
\hline & Kpr 14 & $\mathrm{Kj} 14$ & Iso 1 & DH5 $\alpha$ & $\mathrm{W} 3110 \mathrm{Nal}^{\mathrm{R}}$ \\
\hline Ampicillin & $>128$ & $>128$ & $>128$ & 2 & 1 \\
\hline Mezlocillin & $>128$ & $>128$ & $>128$ & 0.5 & 1 \\
\hline Piperacillin & $>64$ & $>64$ & $>64$ & $0 \cdot 25$ & 1 \\
\hline Cefazolin & $>128$ & $>128$ & $>128$ & 2 & 2 \\
\hline Cefotiam & $>128$ & $>64$ & 32 & 1 & $0 \cdot 5$ \\
\hline $\begin{array}{l}\text { Cefoxitin } \\
\text { Cefotetan } \\
\text { Moxalactam }\end{array}$ & $\begin{array}{r}32 \\
2 \\
4\end{array}$ & $\begin{array}{l}4 \\
2 \\
2\end{array}$ & $\begin{array}{l}2 \\
1 \\
1\end{array}$ & $\begin{array}{l}1 \\
0 \cdot 5 \\
0 \cdot 25\end{array}$ & $\begin{array}{l}1 \\
0 \cdot 5 \\
0 \cdot 25\end{array}$ \\
\hline $\begin{array}{l}\text { Cefotaxime (CTX) } \\
\text { Desacetylcefotaxime } \\
\text { Ceftazidime (CTZ) } \\
\text { Ceftriaxone } \\
\text { Cefmenoxime } \\
\text { Cefpirome }\end{array}$ & $\begin{array}{r}>128 \\
>128 \\
64 \\
>128 \\
>128 \\
32\end{array}$ & $\begin{array}{r}32 \\
64 \\
16 \\
16 \\
16 \\
4\end{array}$ & $\begin{array}{r}64 \\
128 \\
8 \\
16 \\
16 \\
8\end{array}$ & $\begin{array}{l}0 \cdot 25 \\
0 \cdot 5 \\
0 \cdot 25 \\
0 \cdot 25 \\
0 \cdot 25 \\
0 \cdot 125\end{array}$ & $\begin{array}{l}0 \cdot 25 \\
0 \cdot 5 \\
0 \cdot 25 \\
0 \cdot 25 \\
1 \\
0 \cdot 125\end{array}$ \\
\hline Aztreonam & 16 & 0.5 & 2 & $0 \cdot 25$ & $0 \cdot 25$ \\
\hline Imipenem & 1 & 0.5 & $0 \cdot 25$ & $0 \cdot 125$ & $0 \cdot 25$ \\
\hline $\begin{array}{l}\text { Gentamicin } \\
\text { Tobramycin }\end{array}$ & $\begin{array}{r}2 \\
>128\end{array}$ & $\begin{array}{l}0 \cdot 5 \\
4\end{array}$ & $\begin{array}{l}1 \\
1\end{array}$ & $\begin{array}{l}0.25 \\
0.25\end{array}$ & $\begin{array}{l}0.5 \\
0.25\end{array}$ \\
\hline Ciprofloxacin & 0.25 & $0 \cdot 25$ & 0.06 & 0.06 & $0 \cdot 125$ \\
\hline Doxycyclin & $>128$ & 2 & 0.5 & 0.5 & 1 \\
\hline $\begin{array}{l}\text { Trimethoprim/ } \\
\text { sulfamethoxazole }\end{array}$ & $\begin{array}{l}3 \cdot 2 / \\
60 \cdot 8\end{array}$ & $\begin{array}{c}0 \cdot 8 / \\
15 \cdot 2\end{array}$ & $\begin{array}{l}0.025 / \\
0.48\end{array}$ & $\begin{array}{l}0.025 / \\
0.48\end{array}$ & $\begin{array}{l}0.025 / \\
0.48\end{array}$ \\
\hline
\end{tabular}

${ }^{*} \mathrm{Kpr} 14, \mathrm{CTX}^{\mathrm{R}} \mathrm{K}$. pneumoniae isolate; $\mathrm{Kj} 14$, transconjugant harbouring original plasmid pZMP1 from Kpr 14; Iso 1, transformant harbouring recombinant plasmid pZMP1-1-1; DH5 $\alpha, E$. coli recipient of transformation; W3110Nal,$E$. coli recipient of conjugation. 


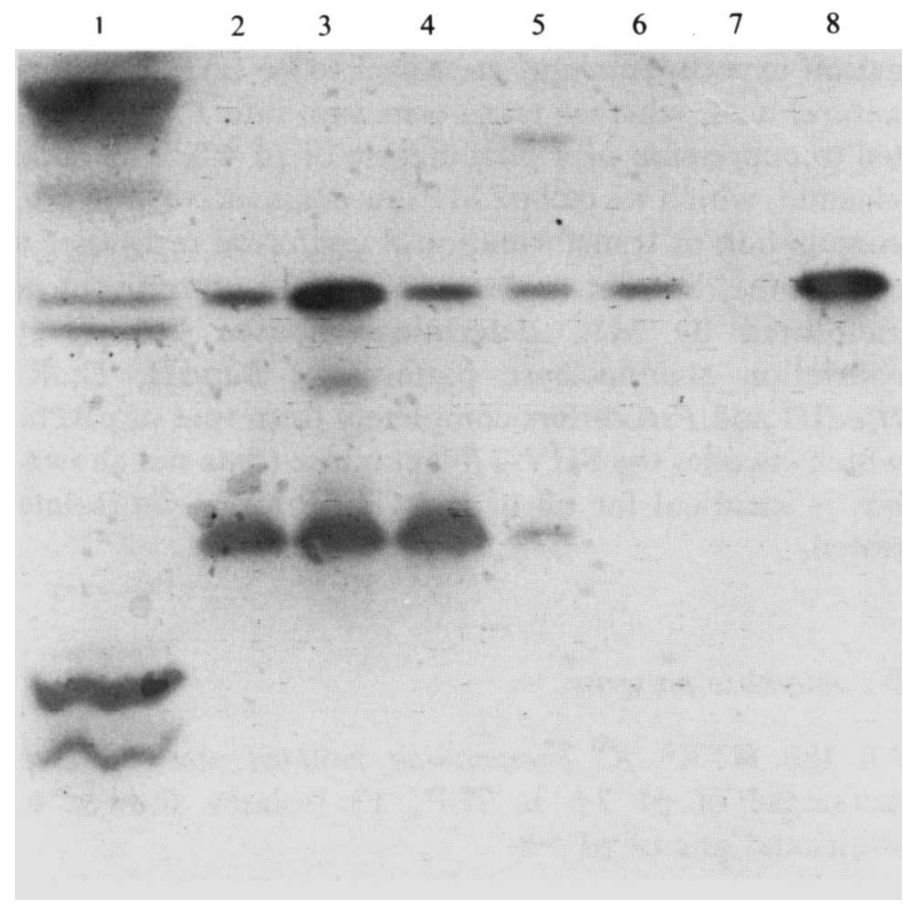

Fig. 1. Analytical IEF of $\beta$-lactamases produced by $\mathrm{CTX}^{\mathrm{R}} K$. pneumoniae isolates from clinical specimens and recipients of transformants. Lane 1, pI reference $\beta$-lactamases (from bottom to top): TEM-1 (pI 5.4), TEM-2 (pI 5.6), OXA-1 (pI 7.4), SHV-1 (pI 7.6), Enterobacter cloacae $\mathrm{P} 99$ chromosomal $\beta$-lactamase (pI 8.8); lanes 2 to $5, \mathrm{CTX}^{\mathrm{R}} K$. pneumoniae isolates (Kpr 12, Kpr 14, Kpr 18, Kpr 9). Lane 6, E. coli DH5 $\alpha$ transformant harbouring natural plasmid pZMP1 (which encodes the new SHV-type $\beta$-lactamase) from Kpr $12=$ tf 12 (the other transformants displayed identical bands, not shown). Lane 7, E. coli DH $5 \alpha$, recipient of transformation; lane $8, E$. coli DH $5 \alpha$ harbouring recombinant plasmid pZMP1-1-1 (containing a $2.2 \mathrm{~kb}$ cluster of adjacent PstI fragments of pZMP1-1) which was excised from the IEF gel and tested in a photometric $\beta$-lactamase assay.

All transconjugants and transformants, irrespective of whether they had been transformed with the original plasmid pZMP1 or a recombinant derivative, possessed only the $\beta$-lactamase of pI 7.6 (Fig. 1).

The expression of the pI $5.9 \beta$-lactamase could be transferred only by conjugation. The transconjugants remained free of plasmids; thus this enzyme is presumed to be chromosomally encoded. It hydrolysed penicillin and ampicillin fairly well, cephaloridine only slowly $\left(K_{\mathrm{m}}\right.$ $>1000 \mu \mathrm{M})$ and CTX and CTZ not at all when crude lysates of the specific transconjugants were monitored. It was not investigated further.

\section{Molecular cloning of the $\beta$-lactamase gene, restriction enzyme mapping and nucleotide sequencing}

pZMP1 was digested with BamHI, and the resulting fragments were cloned into the BamHI site of pLG339. The recombinant plasmids were used to transform $E$. coli DH $5 \alpha$ with selection by CTX and tetracycline. Only one fragment of $3.6 \mathrm{~kb}$ encoded the $\beta$-lactamase.

A restriction map of the cloned $3.6 \mathrm{~kb}$ BamHI fragment was established for EcoRV, MraI, PstI, SalI and StuI (Fig. 2). BglII, EcoRI, HindIII, HpaI, SacI, $S c a I, S m a I, S p h I, X b a I$ and $X h o$ I did not cut within the $3.6 \mathrm{~kb}$ fragment.

Further subcloning of the partially or completely PstIdigested $3.6 \mathrm{~kb} \mathrm{BamHI}$ fragment into pBGS18 led to $\mathrm{CTX}^{\mathrm{R}}$ clones when the three adjacent PstI fragments of

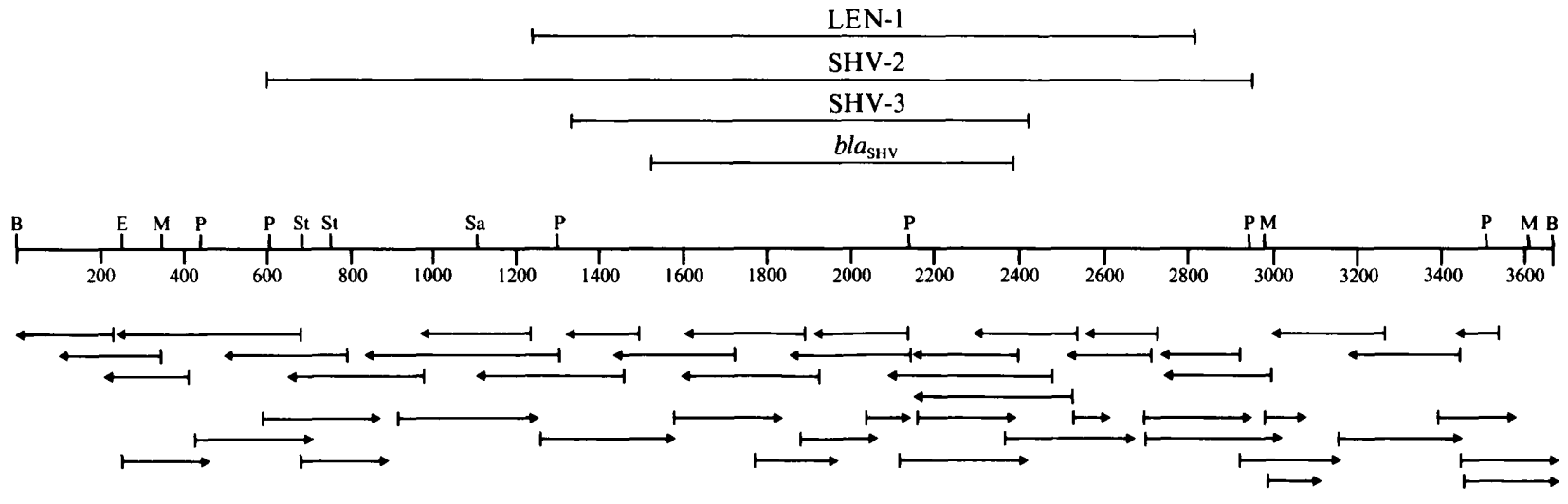

Fig. 2. Restriction endonuclease map of the $3.6 \mathrm{~kb}$ BamHI-fragment encoding the new SHV-type $\beta$-lactamase and sequencing strategy exerted on it. Restriction sites are as follows: B, BamHI; E, EcoRV; M, MraI; P, PstI ; Sa, SalI; St, StuI. Numbers mark nucleotide positions starting from the $5^{\prime}$ end of the fragment. Arrows indicate the direction and length of individual sequencing assays. Horizontal bars above the map represent the extent and corresponding position of the nucleotide sequences of the LEN-1, SHV-2, SHV-3 genes and SHV $\beta$-lactamase structural gene. 


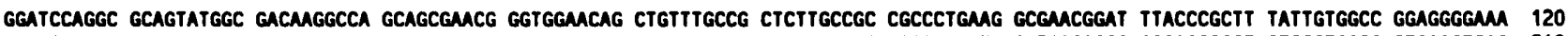
CGICGAGCAT TGTGGCGCAG ACCCTGGGGG TTGAGGCGTT CCATATTGGG CCGACCATCT CCCCTGGCGT GCCCTGGGTG CGTGACACCC GCCAGCCGCT CTCCCTGGCG CTGAGTCAG 240 GTACTTCGG CGATATCCAG TTCTTTGCCC GTGCCCAGCA GGAGTTTCGT CATGACTGAG CAACACTGC GAGAGGAMT GGTGCAGATT GGCGCCTCGT TGTTTAGCCG CGGCTATGCC 360 ACCGGCTCCG CTGGCAATT GTCGCTGCTG CTGCCGGACG GCAACCTGCT GGCGAGCCCG ACCGGCGCCT GCCTCGGCG ACTGCAGGCT CAGCGGTTGT CGGTGGTGAC GCTGCAMGG 480 GMTGGATCT CCGGCGACM ACCGTCGMA GAGGTCACTT TTCACCGGGC GGTCTATTTG CACACCCGG CCTGCAAGC GATCGGTCCA CTTGCACAGC CACTATCTGA CCGCGCTCTC 600 CTGCCTGCAG GGGCTTCGAT CCGCACMCT GGGCAGCTGT TGCAMGTTA GCGATGAGGC AGCCTTTTGT CTTATTCAMA GGCCTTACAT TICAMAMCT CTGCTTACCA GGCGCATTTC 720 GCCCAGGGGA TCACCATMT MMATGCTGA GGCCTGGCCT TTGCGTAGTG CACGCATCAC CTCMTACCT TTGATGGTGG CGTMAGCCGT CTTCATGGAT TTMMACCCA GCGTGGCGCC 840 GATTATCCGT TICAGTTTGC CATGATCGCA TTCAATCACG TTGTTCCGgT ACTIMATCTG TCGGTGTTCA ACGTCAGACG GGCACCGGCC TICGCGTTTG AGCAGAGCA GCGCGCGACC 960 ATAGGCGGGC GCTTTATCCG TGTTGGATGA ATCGCGGGAT CTGCCACTTC TTCACGTTGT TGAGGATtIT ACCCAGAMC CGGTATGCAG CTTTGCTGTT ACGACGGGA GAGAGATAM 1080

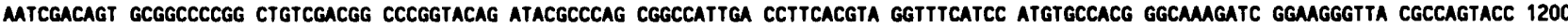
AGCGCAGCCG TITTTCCATT TCAGGCGCAT MACGCTGAC CCAGCGGTA ATCGTGGAGT GATCGACATT CACTCCGCGT TCAGCCAGCA TCTCCTGCAG CTCACGGTA CTGATGCCGT 1320 ATTTGCAGTA CCAGCGTACG GCCCACAGM TGATGTCACG CTGMMTGC CGGCCTTTGa ATGGGTTCAT GTGCAGCTCC ATCAGCMM GGGGATGATA AGTTTATCAC CACCGACTAT 1440 ITGCAMCAGT GCCACGCCG GGTIATTCTT ATITGTCGCT ICTTTACTCG CCTTTATCGG CCTTCACTCA AGGATGIATT GTGGTTATGC GTTATATTCG CCTGTGTATT ATCTCCCTGT 1560 TAGCCACCCT GCCGCTGGCG GTACACGCCA GCCCGCAGCC GCTTGAGCM ATTAMCAM GCGMAGCCA GCTGTCGGGC CGCGTAGGCA TGATAGAMT GGATCTGGCC AGCGGCCGCA 1680 CGCTGACCGC CTGGCGCGCC GATGACGCT TTCCCATGAT GAGCACCTTT MMGTAGTGC TCTGCGGCGC AGTGCTGGCG CGGGTGGATG CCGGTGACGA ACAGCTGGAG CGAMGATCC 1800 ACTATCGCCA GCAGGATCTG GTGGACTACT CGCCGGTCAG CGAMACAC CTTGCCGACG GCATGACGGT CGGCGACTC TGCGCCGCCG CCATTACCAT GAGCGATAC AGCGCCGCCA 1920 ATCTGCTGCT GGCCACCGTC GGCGGCCCCG CAGGATTGAC TGCCTTTTTG CGCCAGATCG GCGACACGT CACCCGCCTT GACCGCTGGG MACGGACT GMATGAGCG CTTCCCGGCG 2040 ACGCCCGCGA CACCACTACC CCGGCCAGCA TGGCCGCGAC CCTGCGCMG CTGCTGACCA GCCAGCGTCT GAGCGCCCGT TCGCMCGGC AGCTGCTGCA GTGGATGGT GACGATCGGG 2160 TCGCCGGACC GTTGATCCGC TCCGTGCTGC CGGCGGGCTG GTTTATCGCC GATAMGACCG GAGCTAGCGA GCGGGGTGCG CGCGGGATTG TCGCCCTGCT TGGCCCGAT MACAMGCAG 2280 AGCGCATTGT GGTGATTTAT CTGCGGGATA CGCCGGCGAG CATGGCCGAG CGMATCAGC MATCGCCGG GATCGGCGCG GCGCTGATCG AGCACTGGCA ACGCTAGCC GGCGGTGGCC 2400 GCGCGCGTTA TCCGGCCCGC AGCACCTCGC AGGCGTGCCG GGCGATATGA CTGGCGGCGG CATCGGMAG ATGCCGGTCG GTMATGATGG TGGTGMCCG GGTCMAGGT MACGCCATM 2520 ACGTGGCCAC CTGATTGTAT TTCGACTGT CGCACAGCAG GATGCTTCTC GCGCTGACCT GGCTGACGGT CTCCTTGACG GTMCCTTGT TCTCATCAGG GGTGATATC CCGCGACTGT 2640 CCCAGCCGCT GGCGGAGATA MGGCCGTAT CGATAGCCAG GTGGCGTMC GTACGCGCCG CCGATTCGCC CACGCAGGAG CGGTTCTCCC GGCACAGAGT GGCGCCGGTG TGGATCACGC 2760 CGCACTGGCT GGCATCGATC AGCAGCTGGG TTATCTCAMA ATCATTGGTG ACCACCTGGA GATCGTTCCG GTCGAGGATC GCCCGCGCCA GCGCCAGGGT GGTAGTCCCG GCATCCAGAT 2880 AGATGCAACT GTTTTJAGCG ATATGACTCG CCGCCAGCGC GCCGATCGCC TGTTTCTCCT CACTCTGCAG CGTGCTTTTC ACCAGATGAC TGGGTTCCGC GGCCAGCCGG CTGACGGCGC 3000 GTACGCCGCC CGAGACGCTG ACCAGCAGCC CCTGCTCCTC CAGTTTACTG ACGTCCCGAC GGATGGTCAT ATGGGACACG CCCAGGATCT CCGTCAGCTC GTTMATGCTT ACCGCCCACG 3120 CTGCTCCACC AGGGCTAMA TACGCTGATG TCGTTCTATT GGATCACCG CTCTCCCCTT ACCATTTTTT CACACCAGGC GTCACCACCC AGGCTACGGC CCTGGCGACA CCCGGTGTTG 3240 TTATCGCGCT TTGCCGCTGT TITTTACGCT ATTTIAGGGC MGMTCGCC GCCTGTGCAG CCTCTTTCCG CCTGTGMTT TTTTATATTC ATGTGGGTTA TTCGTGATA CTCTCACATA 3360 MATTCACATG ATMCGCTT ATTCTATCAT TAMTCACAT TMITAMCTA ATGTTCACAA GGAGACCAGC ATGGCTGCAC ACACTACGT CTGCGTGATT GGACTGGGTT CAMTGGGCAT 3480

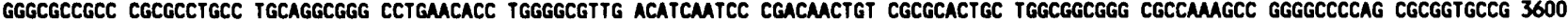
TICGCCGCGG MACTGGATGC AGTTGTGCTG CTGGTGGTCA ATGCCGCCCA GGTGCGGGGA TCC

Fig. 3. Complete nucleotide sequence of the $3663 \mathrm{bp}$ DNA fragment containing $b l a_{\mathrm{SHV} \cdot 2 \mathrm{a}}$. Sequences (partially) homologous to the $-3 \mathrm{~s}$ and -10 boxes of the $b l a_{\mathrm{LEN}-1}$ promoter, Shine-Dalgarno sequence, start and stop codon and putative transcription termination sequences are underlined.

$0 \cdot 84,0.81$ and $0.53 \mathrm{~kb}$ were cloned as a continous insert (pZMP1-1-1; MIC values shown in Table 1) and to $\mathrm{CTX}^{\mathrm{S}}$ clones when the single fragments were cloned as independent inserts. Only the Pst I fragments of 0.84 and $0.81 \mathrm{~kb}$ hybridized to the cloned SHV-2 gene under stringent conditions (data not shown).

Nucleotide sequencing of the total $3.6 \mathrm{~kb} \mathrm{BamHI}$ fragment was accomplished on both strands. The exact size of the fragment is $3663 \mathrm{bp}$ (Fig. 3). It contains six potential open reading frames (ORFs) according to a computerized Fickett analysis, of which the largest, of $858 \mathrm{bp}$, spans the major part of the $0.84 \mathrm{~kb}$ and a minor part of the $0.81 \mathrm{~kb}$ Pst I fragments mentioned above (Fig. 2). It starts at nucleotide no. 1527 of the total sequence, ends at nucleotide no. 2384 and shows $99 \%$ homology to the known nucleotide sequences of SHV-2 (Podbielski \& Melzer, 1990) and SHV-3 (Nicolas et al., 1989) with a difference in 3 and 6 positions, respectively. The nucleotide alterations cluster predominantly within the first 160 positions and the terminal half of the gene. The deduced amino acid sequence of our SHV-type enzyme differs in one and two of 286 positions, respectively, from SHV-2 and SHV-3. The differences in the nucleotide sequence and corresponding amino acid sequence in comparison to SHV-2 and SHV-3 are listed in Table 2. The calculated pI of the new SHV enzyme is exactly the same as that of SHV-2, which corresponds to the results of the IEF gel analysis. The sequence of the $3^{\prime}$ noncoding
Table 2. Differences in nucleotide sequences and deduced amino acid sequences of the $S H V-2,-2$ variant, -3 and $-2 a$ $\beta$-lactamase genes

\begin{tabular}{lccccccccc}
\hline \hline & \multicolumn{10}{c}{ Nucleotide positiont: } \\
\cline { 2 - 10 }$\beta$-Lactamase* & 92 & 153 & 402 & 602 & 672 & 705 & 759 & 762 & 786 \\
\hline SHV-2 & T (L) & C & A & G (R) & C & G & C & T & C \\
SHV-2 variant & A (Q) & G & G & G (R) & T & G & C & T & G \\
SHV-3 & T (L) & C & A & T (L) & C & A & G & C & G \\
SHV-2a & A (Q) & C & G & G (R) & C & G & C & T & G \\
\hline \hline
\end{tabular}

* Data from the folowing sources: SHV-2, Podbielski \& Melzer (1990); SHV-2 variant, Garbarg-Chenon et al. (1990); SHV-3, Nicolas et al. (1989); SHV-2a, this paper.

$\dagger$ Position numbers according to the coding sequence of SHV-3. Letters for nucleotide and amino acids (in brackets) are according to IUPAC Nomenclature.

region in comparison to the corresponding largest known sequence (SHV-2) exhibits only 4 exchanges in 566 nucleotides and no deletions or insertions; thus, the potential transcription termination sequences found for SHV-2 are conserved.

When comparing the $5^{\prime}$ upstream sequence of the new $\beta$-lactamase gene to the corresponding SHV-2 sequence, 72 of 73 nucleotides immediately upstream from the start codon ATG are identical. This region comprises the Shine-Dalgarno sequence and a putative -10 box 

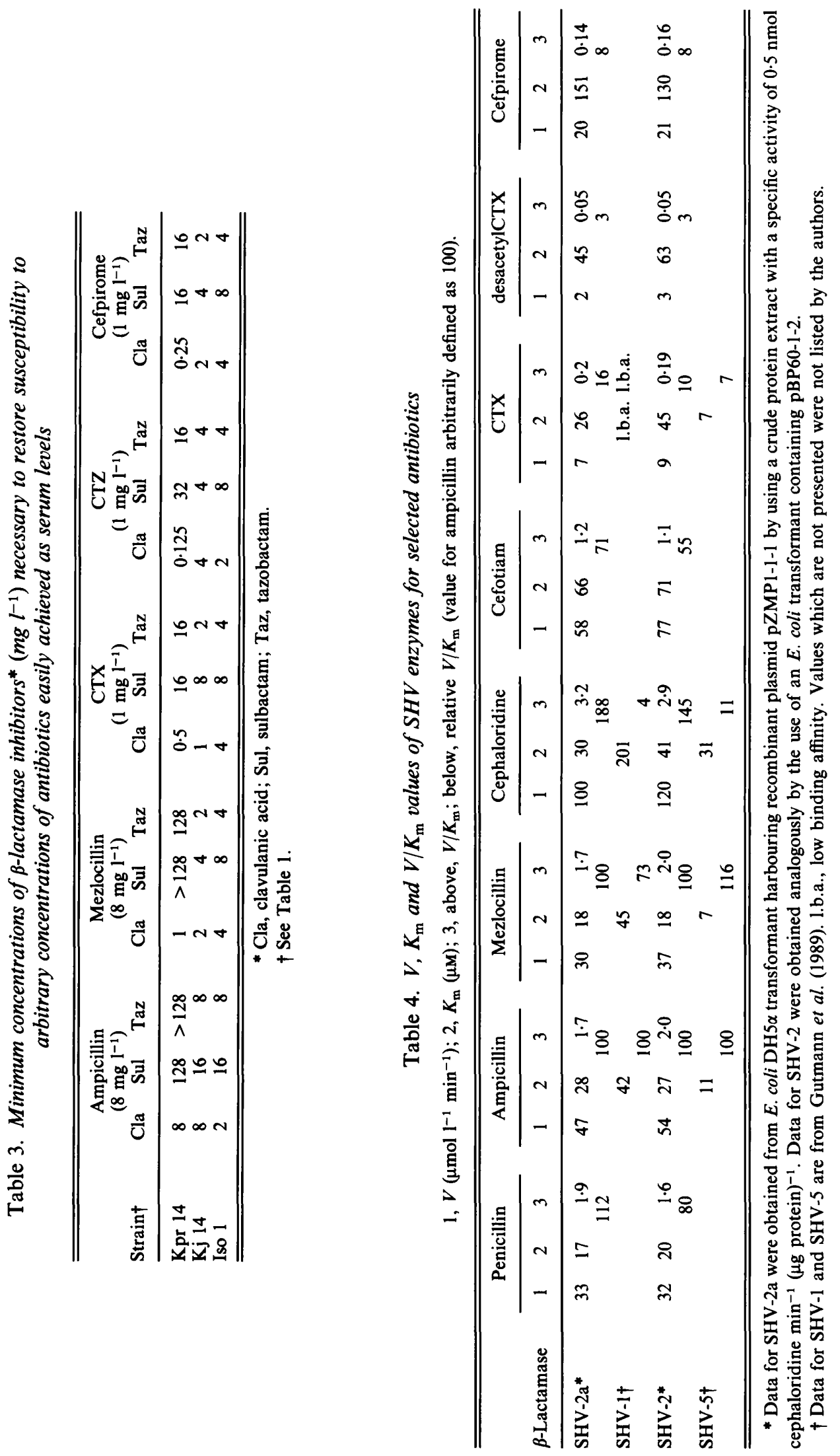
homologous to the promoter of LEN-I (Arakawa et al. 1986). Beyond this point the homology drops abruptly below $50 \%$.

Another SHV-2 variant of Salmonella typhimurium, recently characterized by Garbarg-Chenon et al. (1990), differs in its structural gene from our enzyme in only two nucleotide positions, with no consequence upon the amino acid sequence, whereas the $5^{\prime}$ and $3^{\prime}$ noncoding regions are identical in 219 of 223 and 23 of 30 positions, respectively. On the basis of these pronounced similarities to the SHV-2 $\beta$-lactamases already characterized, our enzyme is considered to be an SHV-2 variant and designated 'SHV-2a'.

Using the five ORFs other than that of the SHV-2a gene as a base for a computer homology search and comparing them to the available sequences of transposases, resolvases and other genes encoded on bacterial transposons as well as to the most recent update of the EMBL databank (release 21), no homology on a minimum level of $60 \%$ could be found.

\section{Determination of MICs, reaction to $\beta$-lactamase inhibitors} and kinetic data

The MIC values for the $\mathrm{CTX}^{\mathrm{R}} K$. pneumoniae isolates (Table 1) reveal resistance or intermediate susceptibility to amino- and acylureidopenicillins, and to cephalosporins of the cephalothine, cefuroxime and the methoxyimino groups (with the exception of cefpirome). The isolates are also resistant to tobramycin and tetracyclines. They show susceptibility to the cephamycins, monobactams, carbapenems, quinolones and gentamicin. The MIC values, especially those of CTX and tobramycin, for a given isolate did not vary significantly when tested immediately after isolation and after 30 and 50 passages on selective medium, thus ruling out laboratory-induced enhancement of CTX resistance.

The transconjugants and transformants containing the original plasmid pZMP1 exhibited a twofold reduced resistance to the methoxyimino-cephalosporins compared to the original CTX ${ }^{\mathrm{R}} K$. pneumoniae strains, but no resistance to tetracyclines or tobramycin.

Each $\beta$-lactamase producing strain was susceptible to the action of commonly available $\beta$-lactamase inhibitors. The assay according to Gutmann et al. (1989) for restoration of susceptibility to arbitrary concentrations of antibiotics demonstrates (Table 3) that the clinical isolate $\mathrm{Kpr} 14$ can tolerate distinctly higher concentrations of sulbactam and tazobactam but not clavulanic acid in comparison to the transconjugant $\mathrm{Kj} 14$ harbouring pZMP1, and transformant Iso 1 harbouring pZMP1$1-1$. Furthermore one can deduce that the $\beta$-lactamase is most susceptible to clavulanic acid whereas tazobactam
Table 5. Apparent $K_{\mathrm{i}}$ and $I_{50}$ values of $S H V$ enzymes for the $\beta$-lactamase inhibitors clavulanic acid $(\mathrm{Cla})$, sulbactam $(\mathrm{Sul})$ and tazobactam $(\mathrm{Taz})$

\begin{tabular}{|c|c|c|c|c|c|c|}
\hline \multirow[b]{2}{*}{$\beta$-Lactamase } & \multicolumn{3}{|c|}{ Apparent $K_{\mathrm{i}}(\mu \mathrm{M})$} & \multicolumn{3}{|c|}{$\mathrm{I}_{50}(\mu \mathrm{M})$} \\
\hline & $\mathrm{Cla}$ & Sul & Taz & $\mathrm{Cla}$ & Sul & Taz \\
\hline SHV-2a* & 0.08 & 0.47 & 0.027 & 0.018 & 0.68 & 0.038 \\
\hline SHV-1† & 0.19 & 1.70 & 0.057 & 0.057 & $7 \cdot 50$ & $0 \cdot 150$ \\
\hline SHV-2* & $0 \cdot 16$ & 0.36 & 0.040 & 0.020 & 0.57 & 0.049 \\
\hline SHV-5† & $0 \cdot 10$ & $0 \cdot 18$ & 0.036 & 0.005 & 0.40 & 0.022 \\
\hline
\end{tabular}

* Data for SHV-2a were obtained from $E$. coli DH5 $\alpha$ transformant harbouring recombinant plasmid pZMP1-1-1 by using a crude protein extract with a specific activity of $0.5 \mathrm{nmol}$ cephaloridine $\mathrm{min}^{-1}(\mathrm{mg}$ protein) $)^{-1}$ and, for $I_{50}$ determination, $200 \mu \mathrm{M}$-cephaloridine as a substrate. Data for SHV-2 were obtained analogously by the use of an E. coli transformant containing pBP60-1-2.

$\dagger$ Data for SHV-1 and SHV-5 are from Gutmann et al. (1989).

and sulbactam are generally active at two- to fourfold higher concentrations.

The $\beta$-lactamase as expressed by the transconjugant containing the original plasmid was inhibited by pHMB when using benzylpenicillin as a substrate but was not inhibited with cephaloridine as substrate or with either substrate by EDTA at concentrations up to $1 \mathrm{mM}$. This indicates a lack of involvement of the thiol group normally present in the active site of serine $\beta$-lactamases (Dalbadie-McFarland et al., 1986; Arakawa et al., 1989) in the catalytic process, and also a $\mathrm{Zn}^{2+}$ independence of the enzyme activity as described for class $A$ enzymes (Ambler, 1980).

The new SHV-type $\beta$-lactamase showed higher apparent $V$ values (Table 4) for older cephalosporins than for penicillins or newer cephalosporins. Its substrate affinity as expressed by $K_{\mathrm{m}}$ values was in the same range for ampicillin, cephaloridine and CTX and compared to these substances less for the rest of the cephalosporins tested. The hydrolytic efficiency as expressed by $V / K_{\mathrm{m}}$ ratio was definitely lower for the newer cephalosporins, especially in comparison to that for ampicillin. There was no detectable hydrolytic activity for cefoxitin, CTZ, aztreonam and imipenem even when the reaction was monitored for $30 \mathrm{~min}$ at 272 and $260 \mathrm{~nm}$ in the case of the CTZ assay. For comparison, values of other SHV enzymes are listed in Table 4.

Analysis of the apparent $K_{i}$ values revealed that the highest affinity of the enzyme was for clavulanic acid, followed by tazobactam and sulbactam (Table 5). The $50 \%$ inhibitory concentration $\left(I_{50}\right)$ values were about 50 to $250 \%$ higher than the apparent $K_{\mathrm{i}}$ values but they paralleled the order of the apparent $K_{\mathrm{i}}$ values. A comparison with values of other SHV enzymes is presented in Table 5. 


\section{Discussion}

The new transferable $\beta$-lactamase reported here is encoded by a $66 \mathrm{~kb}$ plasmid (pZMP1) and confers cefotaxime resistance upon its natural producer $K$. pneumoniae at a level higher than any reported before. Its substrate affinity for methoxyimino-cephalosporins but not cephamycins led to the assumption that it is another member of the emerging SHV $\beta$-lactamase family (Pitton, 1972; Kliebe et al., 1985; Jarlier et al., 1988; Buré et al., 1988; Gutmann et al., 1989); the hybridization and nucleotide sequence data presented above confirm this assumption. The small differences in the nucleotide sequence compared to the established SHV-2 sequence (Podbielski \& Melzer, 1990) demonstrate that the new enzyme is a variant of this protein. As a consequence we propose to name the enzyme SHV-2a. Like the rapidly increasing family of TEM $\beta$-lactamases (Sougakoff et al., 1988a; Mabilat \& Courvalin, 1990) the individual members of the SHV $\beta$-lactamases differ in the level of resistance for different cephalosporins that they confer upon their producers.

SHV-2a confers high resistance to amino- and acylureido penicillins as well as to methoxyimino-cephalosporins but not to cephamycins, monobactams or carbapenems. The preference for methoxyimino-cephalosporins over cephamycins is explained by an amino acid substitution far from the active site of the enzyme leading to new specific side-chain affinities between enzyme and antibiotic (Labia et al., 1988; Philippon et $a l ., 1989)$. Within the group of methoxyimino-cephalosporins the MICs decrease from cefotaxime (CTX) to ceftriaxone, cefmenoxime, ceftazidime (CTZ) and cefpirome, a distribution which resembles that of SHV-2 more than that of SHV-5. The MIC for the natural metabolite of CTX, desacetyl CTX, is slightly higher than that for CTX, a finding which appears to be common for Klebsiella enzymes (Selwyn \& Bakhtiar, 1986).

Differences in membrane permeability between the original $K$. pneumoniae isolates and the $E$. coli transconjugation/transformation recipients probably account for the obvious differences in MIC values for CTX and for the different amounts of the $\beta$-lactamase inhibitors sulbactam and tazobactam necessary to restore susceptibility to $\beta$-lactams (Yoshimura \& Nikaido, 1985). These differences cannot be attributed to the additional chromosomally encoded $\beta$-lactamase of pI 5.9 present in some of the $K$. pneumoniae isolates, since this enzyme does not hydrolyse CTX.

The superior efficacy of clavulanic acid compared to sulbactam and tazobactam for $\beta$-lactamase inhibition documented by the susceptibility restoration assay, especially in the case of the original $K$. pneumoniae isolates, corresponds to general experience (Jacobs et al., 1986; Kitzis et al., 1988) that clavulanic acid has greater affinity for plasmid-encoded $\beta$-lactamases whereas sulbactam and, to a lesser extent, tazobactam bind more avidly to chromosomally encoded enzymes. Analysis of the kinetic data of SHV-2a in comparison to known SHV enzymes discloses an intermediate position of the enzyme concerning the affinity for different penicillins and cephalosporins. These $K_{\mathrm{m}}$ value and the apparent $K_{\mathrm{i}}$ value for sulbactam are generally lower than those for SHV-1 but higher than those for SHV-2 and SHV-5, respectively. The hydrolytic effectivity for CTX is only about $50-100 \%$ higher than that of the newer SHV enzymes, so again the much higher MIC of CTX for our $K$. pneumoniae isolates must be due to effects independent of the $\beta$-lactamase action. The MICs for cefoxitin, CTZ and aztreonam indicating intermediate susceptibility of our $K$. pneumoniae strains (paralleled by no detectable hydrolysis of these agents by the enzyme) may again be caused by a permeability defect especially since the transconjugants/transformants are fully susceptible to cefoxitin and axtreonam. The slightly elevated resistance to CTZ of the transconjugants/transformants harbouring only the SHV-2a $\beta$-lactamase determinant may be ascribed to a trapping phenomenon (Nayler, 1987) exerted on this substance. However, GarbargChenon et al. (1990) measured a low basic hydrolytic activity of their SHV-2 variant enzyme for CTZ $\left(K_{\mathrm{m}}>\right.$ $150 \mu \mathrm{M})$, so it is possible that our enzyme may also have this activity and we did not detect it due to too low a specific concentration of the enzyme in the crude extract or to (absorptive) interference of other substances contained therein.

The order of affinity for different inhibitors of the enzyme expressed by the apparent $K_{\mathrm{i}}$ values and of their effectivity upon the enzyme action expressed by the $I_{50}$ values parallel those of other authors (Kitzis et al., 1988; Gutmann et al., 1989), showing again that the enzyme has highest affinity for clavulanic acid and is most effectively inhibited by this substance. The two- to fivefold differences between the apparent $K_{\mathrm{i}}$ and $\mathrm{I}_{50}$ values of clavulanic acid and tazobactam or sulbactam investigated by the use of protein extracts are in contrast to the more uniform results of the restoration of susceptibility testing, which were achieved by the use of whole bacteria. So the rate of penetration into the periplasmic space may rule out differences in binding affinities of inhibitors to their corresponding enzymes.

The nucleotide sequence of the SHV-2a gene and of the $3^{\prime}$ noncoding region classify SHV-2a as a close relative of the plasmid-coded SHV-enzymes. SHV-2a protein differs from SHV-2 protein only in amino acid residue 10, Gln instead of Leu, and from SHV-3 protein additionally in residue 180, Arg instead of Leu (Table 2). 


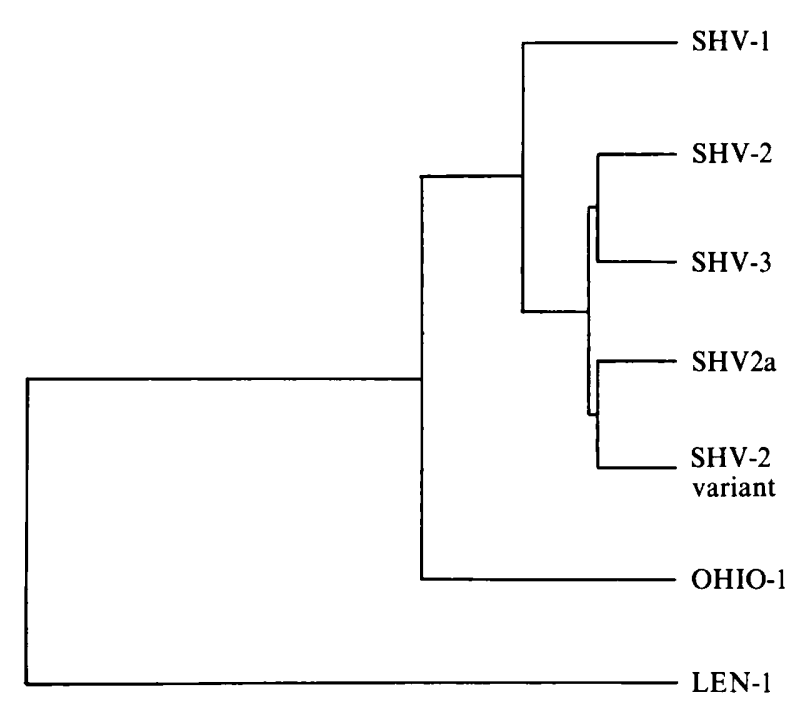

Fig. 4: Dendogram of the nucleotide sequence relatedness of the structural genes of SHV-type $\beta$-lactamases. The horizontal line to LEN-1 represents $10 \%$ difference; the rest of the horizontal lines are in scale. Nucleotide sequences were taken from the following sources: LEN-1 (Arakawa et al., 1986), OHIO-1 (Shlaes et al., 1990), SHV-1 (Mercier \& Levesque, 1990), SHV-2 (Podbielski \& Melzer, 1990), SHV2 variant (Garbarg-Chenon et al., 1990), SHV-2a (this paper), SHV-3 (Nicolas et al., 1989).

When the SHV-2a protein sequence is aligned with that of the Staphylococcus aureus $\beta$-lactamase, for which the crystal structure is known (Herzberg \& Moult, 1987; Sougakoff et al., 1988a), the exchange at residue 10 is far from the pouch of the active site; that at residue 180 is nearer to it without directly contacting it. Since neither of the exchanged residues seem to participate in the formation of the active site or its close vicinity the moderately elevated hydrolytic effectivity of SHV-2a for CTX (50\% more than SHV-2) may be only the result of experimental variation.

The four- to eightfold higher MIC values of transformants expressing SHV-2a compared to those of strains expressing SHV-2 (Kliebe et al., 1985) may be explained by additional quantitative effects, such as enhanced transcription of the SHV-2a gene. Its $5^{\prime}$ upstream sequence differs from all other known SHV nucleotide sequences except the SHV-2 variant of Garbarg-Chenon et al. (1990) starting 74 nucleotides upstream from the start codon, a site that is situated between the -10 and -35 box of the LEN-1 promoter which has been described by Arakawa et al. (1986) for a chromosomally encoded SHV-type enzyme and which is perfectly conserved in the SHV-2 and SHV-3 sequence. Thus, a mutated promoter region of the SHV-2a gene may partially account for the overall MIC value for CTX of bacteria carrying the complete SHV-2a sequence, a situation which would be comparable to the different TEM operons (Sougakoff et al., 1988b).
Considering the phylogeny of plasmid-coded SHV enzymes in regard to the nucleotide sequences of the structural genes (Fig. 4), all these enzymes have an approximately equal distance from the chromosomally encoded LEN-1 enzyme (Arakawa et al., 1986). All SHV genes have the additional $G$ residue 27 nucleotides in front of their common stop codon TAA, rendering the plasmid-encoded enzymes 7 amino acids longer than their chromosomal counterpart. Within the SHV gene family there are three subgroups: (I) SHV-1, (II) SHV-2 and SHV-3 and (III) SHV-2a and SHV-2. The question of ancestral relationship remains unsolved, since we can give no hints about the way of distribution of the gene between the chromosome and obviously different carrier plasmids.

\section{References}

Ambler, R. P. (1980). The structure of $\beta$-lactamases. Philosophical Transactions of the Royal Society B289, 321-331.

arakawa, Y., Ohta, M., Kido, N., Fuji, Y., Komatsu, T. \& Kato, N. (1986). Close evolutionary relationship between the chromosomally encoded $\beta$-lactamase gene of Klebsiella pneumoniae and the TEM $\beta$-lactamase gene mediated by R plasmids. FEBS Letters 207, 69-74.

Arakawa, Y., Ohta, M., Kido, N., Mori, M., Ito, H., Komatsu, T. \& FujII, V. (1989). Chromosomal $\beta$-lactamase of Klebsiella oxytoca, a new class $A$ enzyme that hydrolyzes broad-spectrum $\beta$-lactam antibiotics. Antimicrobial Agents and Chemotherapy 33, 63-70.

Barthélémy, M., PeduziI, J. \& Labia, R. (1988a). Complete amino acid sequence of p453-plasmid-mediated PIT-2 $\beta$-lactamase (SHV1). Biochemical Journal 251, 73-79.

Barthélémy, M., PeduziI, J., Yaghlane, H. B. \& Labia, R. (1988b). Single amino acid substitution between SHV-1 $\beta$-lactamase and cefotaxime-hydrolysing SHV-2 enzyme. FEBS Letters 231, 217-220.

BiRNBOIM, H. C. (1983). A rapid alkaline extraction method for the isolation of plasmid DNA. Methods in Enzymology 100, 243-255.

BROOKS, J. E. (1987).Properties and uses of restriction endonucleases. Methods in Enzymology 152, 113-129.

Buré, A., Legrand, P., Arlet, G., Jarlier, V., Paul, G. \& PhilipPon, A. (1988). Dissemination in five French hospitals of Klebsiella pneumoniae serotype K25 harbouring a new transferable enzymatic resistance to third generation cephalosporins and aztreonam. European Journal of Clinical Microbiology 7, 780-782.

Bush, K. \& SYKES, R. (1986). Methodology for the study of $\beta$ lactamases. Antimicrobial Agents and Chemotherapy 30, 6-10.

Chen, S. T. \& Clowes, R. C. (1984). Two improved promoter sequences for the $\beta$-lactamase expression arising from a single basepair-substitution. Nucleic Acids Research 12, 3219-3234.

Dalbadie-McFarland, G., Neitzel, J. J. \& Richards, J. H. (1986). Active-site mutants of $\beta$-lactamase : use of an inactive double mutant to study requirements for catalysis. Biochemistry 2, 332-338.

Garbarg-Chenon, A., Godard, V., Labia, R. \& Nicholas J. C. (1990). Nucleotide sequence of SHV-2 $\beta$-lactamase gene. Antimicrobial Agents and Chemotherapy 34, 1444-1446.

Gutmann, L., Ferré, B., Goldstein, F. W., Rizk, N., PintoSchuster, E., ACAR, J. F. \& Collatz, E. (1989). SHV-5, a novel SHV-type $\beta$-lactamase that hydrolyzes broad-spectrum cephalosporins and monobactams. Antimicrobial Agents and Chemotherapy 33, 951-956.

HaNAHAN, D. (1983). Studies on transformation of Escherichia coli with plasmids. Journal of Molecular Biology 166, 557-580.

HAWLEY, D. K. \& MCCluRE, W. R. (1983). Compilation and analysis of Escherichia coli promoter DNA sequences. Nucleic Acids Research 11, 2237-2255. 
Herzberg, D. \& Moult, J. (1987). Bacterial resistance to $\beta$-lactam antibiotics: crystal structure of $\beta$-lactamase from Staphylococcus aureus $\mathrm{PCI}$ at $2.5 \AA$ resolution. Science 236, 694-701.

JaCoBs, M. R., ARonoff, S. C., Johenning, S., Shlaes, D. M. \& YAMABE, S. (1986). Comparative activities of the $\beta$-lactamase inhibitors YTR 830, clavulanate, and sulbactam combined with ampicillin and broad spectrum penicillins against defined $\beta$ lactamase-producing aerobic gram-negative bacilli. Antimicrobial Agents and Chemotherapy 29, 980-985.

Jarlier, V., Nicolas, M. H., Fournier, G. \& Philippon, A. (1988). Extended broad-spectrum $\beta$-lactamases conferring transferable resistance to newer $\beta$-lactam agents in Enterobacteriaceae: hospital prevalence and susceptibility patterns. Reviews of Infectious Diseases $10,867-878$.

Kitzis, M. D., Billot-Klein, D., Goldstein, F. W., Williamson, R., Tran van Nhieu, G., Carlet, J., Acar, J. F. \& Gütmann, L. (1988). Dissemination of the novel plasmid-mediated $\beta$-lactamase CTX-1, which confers resistance to broad-spectrum cephalosporins, and its inhibition by $\beta$-lactamase inhibitors. Antimicrobial Agents and Chemotherapy 32, 9-14.

Kliebe, C., Nies, B. A., Meyer, J. F., TolXdorff-Neutzling, R. M. \& WiEDEMANN, B. (1985). Evolution of a plasmid-coded resistance to broad spectrum cephalosporins. Antimicrobial Agents and Chemotherapy 28, 302-307.

Knothe, H., Shah, P., Krcmery, V., Antal, M. \& Mitsuhashi, S. (1983). Transferable resistance to cefotaxime, cefoxitin, cefamandole, and cefuroxime in clinical isolates of Klebsiella pneumoniae and Serratia marcescens. Infection 11, 315-317.

labia, R., Fabre, C., Masson, J. M., Barthélémy, M, Heitz, M. \& PItTon, J. S. (1979). Klebsiella pneumoniae strains moderately resistant to ampicillin and carbenicillin : characterization of a new $\beta$ lactamase. Journal of Antimicrobial Chemotherapy 5, 375-382.

Labia, R., Morand, A., Tiwari, K., Sirot, J. D. \& Petit, A. (1988). Interactions of new plasmid-mediated $\beta$-lactamases with thirdgeneration cephalosporins. Reviews of Infectious Diseases 10, 885891.

Mabilat, C. \& Courvalin, P. (1990). Development of 'oligotyping' for characterization and molecular epidemiology of TEM $\beta$-lactamases in members of the family Enterobacteriaceae. Antimicrobial Agents and Chemotherapy 34, 2210-2216.

Matthew, M., HarRis, A. M. Marshall, M. J. \& Ross, G. W. (1975). The use of analytical isoelectric focusing for detection and identification of $\beta$-lactamases. Journal of General Microbiology 88, 169-178.

Matthew, M., Hedges, R. W. \& SMITH, J. T. (1979). Types of $\beta$ lactamase determined by plasmids in gram-negative bacteria. Journal of Bacteriology 138, 657-662.

Mercier, J. \& LeVESQUe, R. C. (1990). Cloning of SHV-2, OHIO-1, and OXA-6 $\beta$-lactamases and cloning and sequencing of SHV-1 $\beta$-lactamase. Antimicrobial Agents and Chemotherapy 34, 1577-1583.

NAYLER, J. H. C. (1987). Resistance to $\beta$-lactams in gram-negative bacteria: relative contributions of $\beta$-lactamase and permeability limitations. Journal of Antimicrobial Chemotherapy 19, 713-732.

Nicolas, M. H., Jarlier, V., Honore, N., Philippon, A. \& Cole, S. T. (1989). Molecular characterization of the gene encoding SHV-3 $\beta$-lactamase responsible for transferable cefotaxime resistance in clinical isolates of Klebsiella pneumoniae. Antimicrobial Agents and Chemotherapy 33, 2096-2100.

Philippon, A., LABIA, R. \& JACOBY, G. (1989). Extended spectrum $\beta$-lactamases. Antimicrobial Agents and Chemotherapy 33, 1131-1136.

PITTON, J. S. (1972). Mechanisms of bacterial resistance to antibiotics. Reviews in Physiology 65, 15-93.
Podbielski, A. \& Melzer, B. (1990). Nucleotide sequence of the gene encoding the SHV-2 $\beta$-lactamase (bla SHV-2 $_{\text {) }}$ of Klebsiella ozaenae. Nucleic Acids Research 18, 4916.

Podbielski, A., Leusch, H. G., Berndt, R. \& HaAse, G. (1988). Analysis of $\beta$-lactamase activity and plasmid profile of nosocomial isolates of cefotaxime resistant Klebsiella pneumoniae. Zentralblatt für Bakteriologie und Hygiene, Series A 268, 555.

PodbielsKi, A., HaAse, G. \& BeRndT, R. (1989). An improved brothmicrodilution procedure for testing metal ion resistance of Klebsiella pneumoniae. Zentralblatt für Hygiene 189, 147-150.

Podbielski, A., Leusch, H. G., Warnatz, K., Melzer, B. \& HaAse, G. (1990). Characterization of a new Klebsiella pneumoniae SHV- $\beta$ lactamase gene responsible for high-level cefotaxime resistance. Zentralblatt für Bakteriologie 273, 115.

Podschun, R., Heineken, P., Ullmann, U. \& Sonntag, H. G. (1986). Comparative investigations of Klebsiella species of clinical origin: plasmid patterns, biochemical reactions, antibiotic resistance and serotypes. Zentralblatt für Bakteriologie und Hygiene, Series A 262 , 335-345.

Ross, G. W. \& O'Callaghan C. H. (1975). $\beta$-lactamase assays. Methods in Enzymology 47, 69-85.

Roy, C., Segura, C., Tirado, M., Reig, R., Hermida, M., Teruel, D. \& Foz, A. (1985). Frequency of plasmid-determined beta-bactamases in 680 consecutively isolated strains of Enterobacteriaceae. European Journal of Clinical Microbiology 4, 146-147.

SambrooK, J., Fritsch, E. F. \& Maniatis, T. (1989). Molecular Cloning: a Laboratory Manual, 2nd edn. Cold Spring Harbor, NY: Cold Spring Harbor Laboratory.

SANGer, F., Nicklen, S. \& Coulson, A. R. (1977). DNA sequencing with chain terminating inhibitors. Proceedings of the National Academy of Sciences of the United States of America 74, 5463-5467.

SeEberG, A. H., TolXdorff-Neutzling, R. M. \& WiedemanN, B. (1983). Chromosomal $\beta$-lactamases of Enterobacter cloacae are responsible for resistance to third generation cephalosporins. Antimicrobial Agents and Chemotherapy 23, 918-925.

SelwYN, S. \& BaKhtiaR, M. (1986). Comparative in vitro studies on cefotaxime and desacetylcefotaxime. Drugs in Experimental and Clinical Research 12, 953-965.

Shlaes, D. M., Currie-McCumber, C, Hull, A., Behlau, I. \& Kron, M. (1990). OHIO-1 $\beta$-lactamase is part of the SHV-1 family. Antimicrobial Agents and Chemotherapy 34, 1570-1576.

Spratt, B. G., Hedge, P. J., te Heesen, S., EdelmanN, A. \& BroomeSMITH, J. K. (1986). Kanamycin-resistant vectors that are analogues of plasmids pUC8, pUC9, pEMBL8 and pEMBL9. Gene 41, 337342.

Sougakoff, W., Goussard, S., Gerbaud, G. \& Courvalin, P. $(1988 a)$. Plasmid-mediated resistance to third-generation cephalosporins caused by point mutations in TEM-type penicillinase genes. Reviews of Infectious Diseases 10, 879-884.

Sougakoff, W., Goussard, S. \& Courvalin, P. (1988b). The TEM-3 $\beta$-lactamase, which hydrolyses broad-spectrum cephalosporins, is derived from the TEM-2 penicillinase by two amino acid substitutions. FEMS Microbiology Letters 56, 343-348.

Stoker, N. G., FaIrweatHer, N. F. \& SPRATT, B. (1982). Versatile low-copy-number vectors for cloning in Escherichia coli. Gene 18 , 335-341.

WALEY, S. G. (1982). A quick method for the determination of inhibition constants. Biochemical Journal 205, 631-633.

WALKER, J. M. (1984). Methods in Molecular Biology, vol. 2, Nucleic Acids. Clifton, NJ: Humana Press.

Yoshimura, F. \& NiKaido, H. (1985). Diffusion of $\beta$-lactam antibiotics through the porin channels of Escherichia coli K-12. Antimicrobial Agents and Chemotherapy 27, 84-92. 